Bentham OPEN
CrossMark
Content list available at: www.benthamopen.com/TOMICROJ/
DOI: $10.2174 / 1874285801610010043$

\title{
Editorial
}

\section{Rapid Identification and Characterization of Microbial Pathogens by Molecular Biology Techniques}

Microbial infections including bacterial and viral infections are potentially life-threatening and require rapid identification and characterization of the microorganisms. Rapid and accurate detection of foodborne microorganisms from food, environment and clinical samples requires characterization to the species and/or subspecies level as well as determining their antibiotic susceptibility. These steps are important for: 1) selecting appropriate antibiotics, 2) reducing morbidity and mortality, and 3 ) reducing health care costs.

Traditional microbiological detection starts with an enrichment step usually using a nonselective enrichment that allows injured cells to repair and multiply. These enrichment cultures are then subcultured on selective and differential agars. Typical and suspected colonies are then stained by Gram staining and subsequent biochemical identification, and susceptibility testing are performed. These steps usually take 3-7 days. Identification of virulence factors requires additional time and involves expensive phenotypic and genotypic tests. Traditional microbiological identification methods often do not provide prompt results for optimal early patient diagnosis and treatment management. In recent years, more and more studies have demonstrated the value of molecular biologic techniques to rapidly identify and genotype bacteria or virus in food, environment, and clinical samples. Molecular biology techniques are methods which generally involve the analysis and handling of nucleic acid and other molecules. Compared to traditional microbial identification methods, molecular biology methods can be used to detect and identify microorganisms simultaneously, which results in quicker diagnoses and treatments. The other advantages of molecular methods are that the protocols are of higher sensitivity and specificity.

The aim of this hot topic is to provide an overview of current exciting molecular biology techniques that are employed to rapidly identify and characterize important pathogenic bacteria and viruses. The topic would update knowledge on prompt bacterial and viral identification and characterization methods, which can speed up the diagnosis and treatment of infectious diseases, improve epidemiologic screening, and reduce their morbidity and mortality.

Staphylococcus aureus causes a wide range of suppurative infections, food poisoning and toxic shock syndrome. Methicillin resistant $S$. aureus (MRSA) is resistant to most $\beta$-lactam antibiotics. MRSA infection is more difficult to treat with commonly used antibiotics and thus more dangerous. A recent study showed that about $47 \%$ of the meat and poultry in U.S. grocery stores were contaminated with $S$. aureus with about half of those bacteria being resistant to multiple antibiotics [1]. It is important to precisely and timely detect and identify the organism for epidemical and clinical investigation. Liu et al. outline different PCR-based approaches for MRSA detection in detailed and particular ways.

Bacteroides fragilis is an anaerobic opportunistic pathogen, which cause bacteremia, abscess formation, diarrhea, and inflammatory bowel disease [2]. B. fragilis is the most commonly isolated bacteria in anaerobic infections, especially infections involving gastrointestinal flora. Next generation sequencing and analysis tools can be employed to detect quickly $B$. fragilis. The isolation, detection and characterization methods of Enterotoxigenic $B$. fragilis are clearly outlined by Drs. Fathi and Wu.

Francisella tularensis is a small, nonmobile, Gram-negative bacterium. It is highly infectious, causing lifethreatening tularemia in animals and humans [3]. It is considered by Center for Disease Control and Prevention to be a category A agent [4]. F. tularensis grows slowly, so it requests molecular biology assays to detect rapidly. A review article written by Lai et al. detailed summarize the up-to-date developments of these assays. 
Noroviruses are now recognized as the most common cause of nonbacterial acute gastroenteritis and foodborne viral illness worldwide. Human noroviruses account for over 267 million infections worldwide annually [5]. Noroviruses are extremely infectious; a few viral particles can initiate an infection. A major impediment of the identification and diagnosis of norovirus infection is the lack of an effective cell culture system or small animal models. Molecular techniques have been developed to detect the viruses. The molecular identified and diagnostic methods of noroviruses are meticulously outlined by Drs. Chen and $\mathrm{Hu}$.

The value of molecular biology technique has been demonstrated in identifying and characterizing bacteria and viruses in food, environmental and clinical specimens, and in hastening diagnostic and epidemiological screening procedures, which circumvent the problems of traditional culture methods. Thus, these review articles will updated knowledge on microorganisms, and provide useful and practicable guides for rapid identification and characterization of the bacteria and viruses.

\section{REFERENCES}

[1] Waters AE, Contente-Cuomo T, Buchhagen J, et al. Multidrug-Resistant Staphylococcus aureus in US Meat and Poultry. Clin Infect Dis 2011; 52(10): 1227-30. [http://dx.doi.org/10.1093/cid/cir181] [PMID: 21498385]

[2] Boleij A, Hechenbleikner EM, Goodwin AC, et al. The Bacteroides fragilis toxin gene is prevalent in the colon mucosa of colorectal cancer patients. Clin Infect Dis 2015; 60(2): 208-15. [http://dx.doi.org/10.1093/cid/ciu787] [PMID: 25305284]

[3] Keim PS, Wagner DM. Humans and evolutionary and ecological forces shaped the phylogeography of recently emerged diseases. Nat Rev Microbiol 2009; 7(11): 813-21.

[http://dx.doi.org/10.1038/nrmicro2219] [PMID: 19820723]

[4] Ellis J, Oyston PC, Green M, Titball RW. Tularemia. Clin Microbiol Rev 2002; 15(4): 631-46. [http://dx.doi.org/10.1128/CMR.15.4.631-646.2002] [PMID: 12364373]

[5] Glass RI, Parashar UD, Estes MK. Norovirus gastroenteritis. N Engl J Med 2009; 361(18): 1776-85. [http://dx.doi.org/10.1056/NEJMra0804575] [PMID: 19864676]

Lan Hu

Center for Food Safety and Applied Nutrition U.S Food and Drug Administration U.S.A

Email: lan16686@yahoo.com

\footnotetext{
(C) Lan Hu; Licensee Bentham Open.
}

This is an open access article licensed under the terms of the Creative Commons Attribution-Non-Commercial 4.0 International Public License (CC BY-NC 4.0) (https://creativecommons.org/licenses/by-nc/4.0/legalcode), which permits unrestricted, non-commercial use, distribution and reproduction in any medium, provided the work is properly cited. 